\title{
Biopelícula extrarradicular: reporte de un caso clínico
}

\author{
Carlos Colorado Vélez, Esp. ${ }_{1}$, Rafael Hernández Grisales*, Esp. ${ }_{1}$
}

${ }_{1}$ Facultad de Odontología, Universidad ces. Medellín, Colombia

Recibido: 24 de julio del 2014. Aprobado: 11 de diciembre del 2014.

*Autor de correspondencia: Rafael Hernández Grisales. Facultad de Odontología, Universidad CES, Medellín, Colombia. Calle 10 A n.ํ 22 - 04. Teléfono: (57) 4 4440555. Correo electrónico: raffernandez@yahoo.com

Cómo citar este artículo: Colorado-Vélez C, Hernández-Grisales R. Biopelícula extrarradicular: reporte de un caso clínico. Rev Nac Odontol. 2015;11(20):55-64: doi: http://dx.doi.org/10.16925/od.v11i20.762

Resumen. La biopelícula es una población de células que crecen unidas a una superficie, envueltas por una matriz de exopolisacáridos que las protege del ataque de los antibióticos. Más del $60 \%$ de todas las infecciones microbianas son causadas por biopelículas. El aumento de la resistencia de estas comunidades a los antimicrobianos involucra varios mecanismos, entre los que se incluyen: inactivación de los antibióticos por polímeros extracelulares, disminución de la tasa de crecimiento por limitación de nutrientes y cambios fenotípicos en las células bacterianas, como resultado de la adquisición de genes de resistencia dentro de la biopelícula. El pronóstico para el tratamiento y la erradicación de las biopelículas no es el mejor. El desarrollo de nuevos medicamentos es necesario y urgente para contrarrestar las infecciones en las que la biopelícula está involucrada. En este artículo se presenta el caso de una mujer de 44 años que acude a consulta por dolor en el 12, especialmente a la percusión vertical. Estos episodios tienen su causa en la endodoncia subextendida del 12 y en el material de obturación de conductos que se encuentra extrarradicularmente. Tras la evaluación radiográfica y la ejecución adecuada del plan de tratamiento, se pudieron detectar bacterias en forma de cocos dispuestas en biopelícula, las cuales originaban la infección que presentaba el paciente.

Palabras clave: antibióticos, biopelícula, infección, resistencia. 


\title{
Extrarradicular Biofilm: A Clinical Case Report
}

\begin{abstract}
Biofilm is a group of cells sticking together on a surface, embedded within a matrix of exopolysaccharides protecting them from antibiotics. Over $60 \%$ of microbial infections are caused by biofilms. The antimicrobial resistance increase of these communities involve several mechanisms, including: inactivation of antibiotics through extracellular polymers, decline of the growth rate by nutrient limitation and phenotypic changes in the bacterial cells, as a result of the resistant gene acquisition within the biofilm. Prognosis for treatment and eradication of biofilms is not the best one. The development of new medicines becomes necessary and urgent to counter biofilm related infections. This post shows the case of a 44 year old woman who goes to see the doctor for pain in 12 , particularly upon vertical percussion. Such episodes are caused by under extended endodontics of 12 and in the extraradicular filling material of ducts. After the x-ray evaluation and appropriate application of the treatment plan, spherical shaped bacteria were detected within the biofilm, which caused the patient's infection.
\end{abstract}

Keywords: antibiotics, biofilm, infection, resistance.

\section{Biofilme extra-radicular: relatório de um caso clínico}

Resumo. O biofilme é uma população de células que crescem ligadas a uma superfície, envolvidas por uma matriz de exopolissacarídeos que protege contra o ataque dos antibióticos. Mais de $60 \%$ de todas as infecções microbianas são provocadas pelos biofilmes. O aumento da resistência destas comunidades aos antimicrobianos envolve vários mecanismos. Dentre os quais estão: inativação dos antibióticos por polímeros extracelulares, diminuição da taxa de crescimento por limitação de nutrientes e alterações fenotípicas nas células bacterianas, como resultado da aquisição de genes de resistência dentro do biofilme. O prognóstico para o tratamento e a eliminação dos biofilmes não é o melhor. O desenvolvimento de novos medicamentos é necessário e urgente para combater as infecções nas quais o biofilme está envolvido. Neste artigo apresenta-se o caso de uma mulher de 44 anos que vai à consulta por dor no $12^{\circ}$, especialmente à percussão vertical. Esses episódios têm sua causa endodontia sub-estendida do $12^{\circ}$ e no material de obturação de condutos que se encontra extra-radicularmente. Após a avaliação radiográfica e a execução adequada do plano de tratamento, foi possível detectar bactérias em forma de cocos dispostas em biofilme, as quais provocavam a infecção apresentada pelo paciente.

Palavras-chave: antibióticos, biofilme, infecção, resistência. 


\section{Introducción}

Los microorganismos han desarrollado mecanismos que les permiten sobrevivir en un ambiente de condiciones adversas [1], y que les facilitan escapar de la acción de las células de defensa y del sistema del complemento. Así, evitan la destrucción por parte de los fagocitos, causan inmunosupresión e inducen la proteolísis de los anticuerpos [2]. El modo de crecimiento en biopelículas es una estrategia de supervivencia de los microorganismos frente a las condiciones ambientales adversas [1-3].

Estas agregaciones de microorganismos han sido observadas sobre las paredes de los conductos infectados, lo que sugiere que los mecanismos de formación de las biopelículas pueden existir dentro del espacio del conducto radicular. También han sido señaladas como la causa de periodontitis apical resistente al tratamiento [4-6].

La condición para la formación de la biopelícula en el conducto radicular varía dependiendo de la causa de la destrucción de la pulpa. Una isquemia por trauma, que conlleva una necrosis, es probable que tenga prerrequisitos totalmente diferentes para la fase de colonización que aquellas pulpas expuestas por caries [7].

La primera identificación de biopelículas en conductos infectados se debe a Nair [4], en 1987. Él examinó con un microscopio electrónico de transmisión los conductos radiculares de 31 dientes no tratados endodónticamente que tenían caries coronal y en los cuales el proceso inflamatorio periapical estaba unido al diente en el momento de la extracción. Notó que todos los dientes mostraron bacterias en los conductos radiculares, una microbiota de cocos, bacilos, filamentos y espiroquetas.

En 1990, Tronstad et al. [8] desarrollaron el primer reporte de infección extrarradicular al examinar con microscopio electrónico de barrido (SEM) la superficie de un diente resistente al tratamiento endodóntico.

En 1991, Molven et al. [5] confirmaron los hallazgos previos de Nair [4], al evaluar los $2 \mathrm{~mm}$ más apicales de doce raíces con enfermedad periapical, usando SEM. Dentro de dos conductos radiculares observaron un depósito parecido a una placa de bacterias en múltiples capas, embebidos en una matriz de polímeros extracelulares, probablemente de origen bacteriano. También se encontraron con múltiples formas microbianas, entre las que destacaron la asociación entre los cocos y las formas filamentosas, estructuras denominadas mazorca de maíz, las cuales son descritas para la placa dental.

En 1996, Lomcali et al. [9] observaron la superficie apical de 17 raíces con lesiones periapicales crónicas, demostrables radiográficamente con el uso de SEM. Se observaron zonas con lagunas resortivas en donde se encontraban algunas bacterias y levaduras, así como una placa bacteriana con múltiples capas de bacterias, embebidas en una matriz extracelular densa, ubicada principalmente alrededor del foramen apical principal.

Los autores sugieren que, en estas condiciones, las defensas del hospedero son incapaces de mantener a los microorganismos en el espacio del conducto radicular y que esta placa bacteriana, con su estructura lisa, puede ser un factor importante para el mantenimiento de la inflamación en los tejidos perirradiculares; por esta razón, se debe hacer especial énfasis en su eliminación [9].

En 2001, Siquiera y Lopes [2] observaron 26 dientes extraídos con lesiones periapicales asintomáticas, con el uso de SEM, y evidenciaron la presencia de cocos y bacilos suspendidos en el conducto radicular. En un solo caso se observó un denso agregado bacteriano en el foramen apical, compuesto principalmente por bacilos; en este mismo caso, el agregado bacteriano se extendió más allá del foramen apical, en el que se reconocieron otros morfotipos celulares además de los bacilos, incluyendo coagregaciones de cocos y filamentos, caracterizados en una estructura de mazorca de maíz. Estas observaciones soportaron las evidencias previas reseñadas por Molven et al. [5].

La incidencia de biopelículas perirradiculares fue baja para este estudio (4\%), con lo que se concluye que la infección extrarradicular no es un hallazgo común en dientes no tratados con pulpas infectadas [2]. Resultados similares fueron reportados por Walton y Ardjmand [10], quienes indujeron lesiones periapicales en monos, por exposición pulpar al medio oral. Luego de siete meses, se seccionaron bloques incluyendo los dientes y los tejidos vecinos para ser procesados histológicamente, $y$ en ninguno de los casos observaron bacterias en la lesión o en la superficie radicular externa.

En contraparte, Noiri et al. [11] examinaron la participación de biopelículas extrarradiculares en periodontitis apical persistente, evaluando seis dientes y cinco puntas de gutapercha extruida en la región periapical con el uso del SEM. En nueve de 
las once muestras observadas, se encontraron biopelículas bacterianas en la región extrarradicular.

La superficie de la gutapercha estaba cubierta con una estructura similar a un glicocáliz, en tanto que formas filamentosas, bacilos alargados y espiroquetas fueron las formas más predominantes en los sitios extrarradiculares. En algunos puntos se observó la emigración de células planctónicas del glicocáliz [10].

Estas estructuras, que se encontraron tanto en la gutapercha como en la superficie externa de los dientes, tuvieron que ser formadas con cierto tiempo, lo que sugiere que estas estructuras no son el resultado de contaminación bacteriana durante el proceso de toma de muestra y preparación de los especímenes, y soporta que las biopelículas extrarradiculares están relacionadas con la periodontitis apical persistente [11].

Hallazgos similares fueron reportados en el 2002 por Leonardo et al. [12], quienes evaluaron la presencia de biopelículas bacterianas sobre la superficie externa de los ápices radiculares, en dientes con necrosis pulpar con y sin imagen periapical evidenciable radiográficamente y en dientes con pulpa vital. Las raíces fueron seccionadas y los ápices radiculares (aproximadamente $3 \mathrm{~mm}$ ) fueron procesados con SEM. No se observó la presencia de microorganismos ni biopelículas en los dientes que presentaban pulpa vital y necrosis pulpar sin periodontitis apical evidenciable radiográficamente, mientras que en los dientes con necrosis pulpar con lesión periapical evidenciable en la radiografía, las biopelículas apicales estuvieron siempre presentes.

Una nueva forma de colonización microbiana, que evidencia la presencia de biopelículas en las infecciones endodónticas, fue reportada en el 2002 por Sunde et al. [13], quienes evaluaron la microbiota periapical de 36 dientes con periodontitis apical refractaria. Ninguno de los dientes respondió al tratamiento endodóntico convencional con medicación intraconducto con hidróxido de calcio por un periodo de seis meses; incluso, ocho de los pacientes recibieron antibioticoterapia sistémica. Cerca de la mitad de las bacterias (51\%) fueron anaerobias, en las que la flora periapical estuvo constituida principalmente por especies Gram positivas $(79,5 \%)$.

De acuerdo con estos hallazgos, los microorganismos que habitan en biopelículas en zonas inaccesibles del sistema de conductos radiculares no pueden ser removidos por la instrumentación e irrigación en una sola sesión, lo que demuestra la importancia de la aplicación de todas las medidas químico-mecánicas no antibióticas para tratar con dientes infectados y necróticos, a fin de interrumpir las biopelículas y reducir la carga microbiana intrarradicular al nivel más bajo posible, para esperar un pronóstico favorable del tratamiento de conductos a largo plazo [14].

El propósito del tratamiento endodóntico es la eliminación de la infección del sistema de conductos radiculares y la prevención de la reinfección [15-17]; sin embargo, en ciertas circunstancias el tratamiento endodóntico puede fallar en cumplir su objetivo [15].

Existen factores locales y sistémicos que contribuyen al fracaso del tratamiento endodóntico [15]. No obstante, el factor decisivo que afecta el resultado del tratamiento de conducto a largo plazo es la persistencia de microorganismos dentro del sistema de conductos radiculares [1-7, 15-17], puesto que van a representar un riesgo latente para que el tratamiento fracase y se perpetúe la inflamación perirradicular [17].

Las posibilidades de aumentar un resultado favorable con el tratamiento de conductos son altas si se consigue que la infección sea erradicada efectivamente antes de que el sistema de conductos radiculares sea obturado [12-16]. En caso contrario, los microorganismos se mantendrán viables en el conducto y existirá un riesgo constante de que la inflamación perirradicular sea perpetuada [12-16].

Existen casos en los que se ejecutan todos los procedimientos a cabalidad, cumpliendo todos los estándares del tratamiento de conducto, pero sin tener éxito [16-18]. Se ha sugerido que los resultados poco satisfactorios de los casos aparentemente bien tratados estén asociados con infección intra o extrarradicular, reacciones a cuerpo extraño y quistes verdaderos [10-18]; no obstante, la persistencia de microorganismos parece ser la principal causa de fracaso en la mayoría de los casos [15-18].

Estos microorganismos remanentes pueden encontrarse en las complejidades anatómicas de la morfología de los conductos radiculares como ramificaciones apicales, istmos y otras irregularidades, en las que las bacterias pueden estar presentes en la forma de biopelículas y también pueden ganar acceso a la superficie externa del diente, donde forman biopelículas extrarradiculares para mantenerse viables [15-18]. 


\section{Caso clínico}

Paciente de 44 años de edad, de género femenino, quien consulta al endodoncista por presentar sintomatología severa en el 12, especialmente a la percusión vertical. Con analgesicoterapia, la paciente reporta episodios de mejoría, pero el dolor continúa una vez deja de tomar los medicamentos.

Clínicamente, se observa tramo protésico en metal-porcelana realizado hace dos años y edema en encía vestibular del 12. Diente con antecedentes de tratamiento endodóntico. En radiografía periapical, se observa endodoncia subextendida e imagen radiopaca transapicalmente compatible con material de obturación de conductos radiculares que fue llevado más allá del ápice radicular (figura 1). No presenta salida de tracto sinuoso.

La paciente está en buenas condiciones de salud general; en la anamnesis complementaria no se hallaron desórdenes sistémicos o anomalías en su historia personal ni familiar. En primera instancia, se hizo retratamiento endodóntico del diente 12 , con lo que mejoró notablemente la endodoncia inicial y se logró la obturación del conducto a un nivel adecuado (figura 2). Posteriormente, se realizó cirugía apical para poder remover el material que se encontraba transapicalmente (figuras 3-10), el cual se transfirió a un criovial con $1 \mathrm{ml}$ de una solución al 5\% de dimetil sulfóxido en caldo tripticasa soya (CTS-DMSO), y luego fue transportado al Laboratorio de Microbiología Oral del Instituto Colombiano de Medicina Tropical, para su procesamiento y análisis microbiológico.

Los resultados obtenidos determinaron que la imagen radiopaca transapicalmente era gutapercha, y se detectaron, además, bacterias en forma de cocos, dispuestas en biopelículas inmersas en la gutapercha. Se tomaron fotografías bajo microscopía electrónica de barrido, con lo que se evidenció claramente la formación de las biopelículas (figuras 11-14). Después de la cirugía, la paciente mejoró notablemente y en la radiografía final se observa la buena cicatrización apical (figuras 15-16).

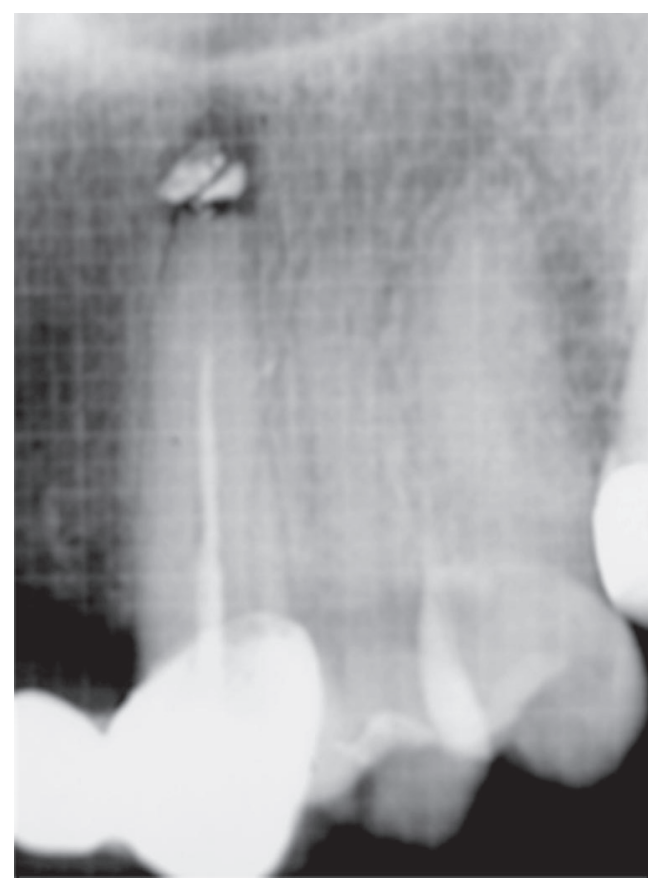

Figura 1. Rx inicial, se observa endodoncia subextendida e imagen radiopaca transapicalmente

Fuente: caso clínico



Figura 2. Se realiza retratamiento endodóntico. Se logra la longitud total del conducto radicular Fuente: caso clínico 


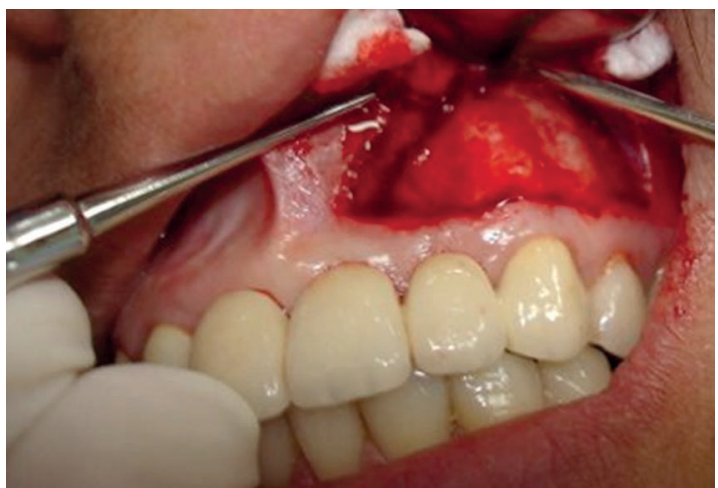

Figura 3. Se realiza colgajo submarginal Fuente: caso clínico

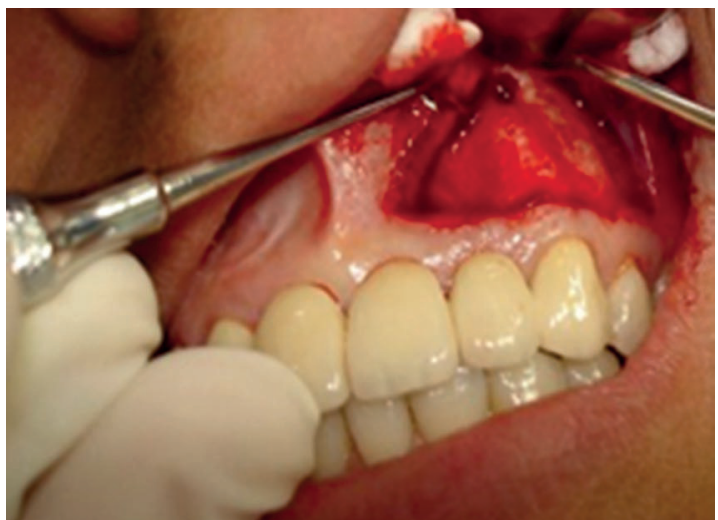

Figura 4. Reabsorción ósea generada por la lesión apical Fuente: caso clínico

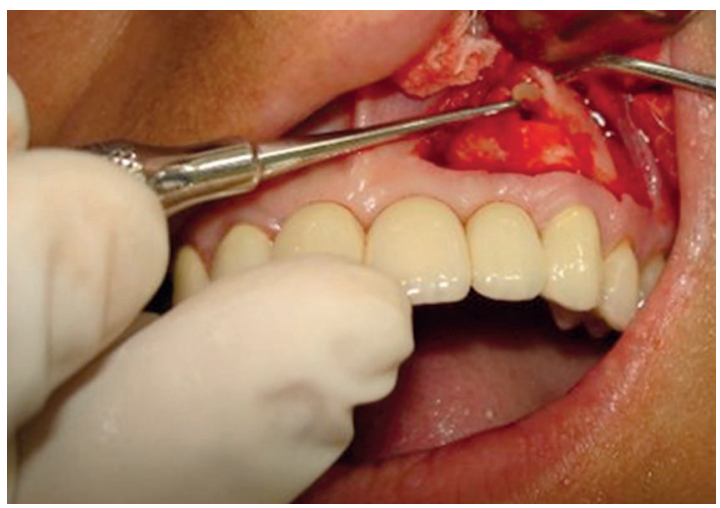

Figura 5. Se remueve el material transapical Fuente: caso clínico

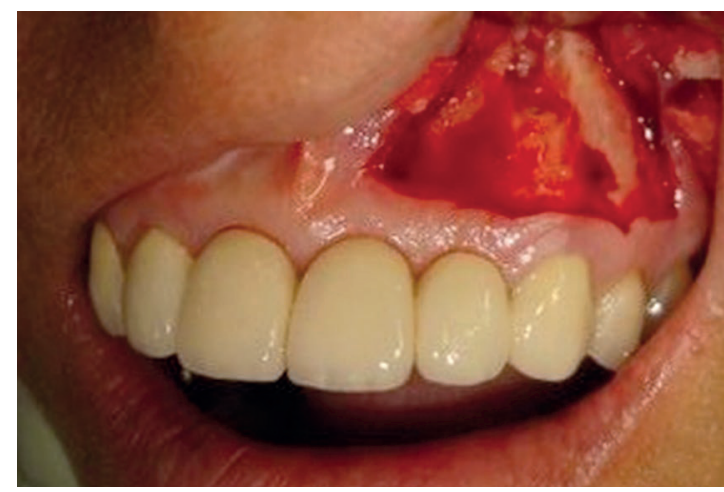

Figura 6. Preparación del ápice radicular Fuente: caso clínico

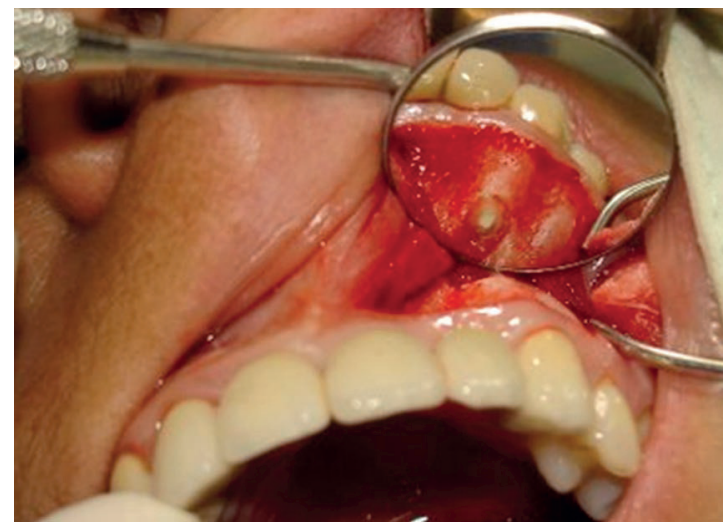

Figura 7. Selle apical con MTA

Fuente: caso clínico

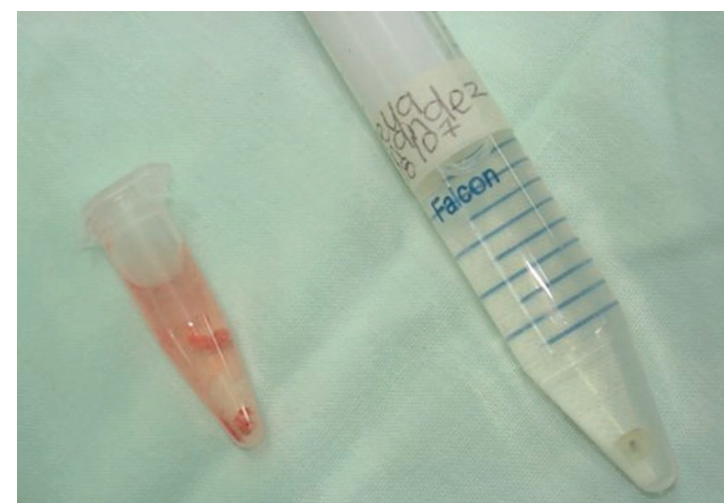

Figura 8. Material transapical para su procesamiento y análisis microbiológico

Fuente: caso clínico 




Figura 9. Reposición del colgajo

Fuente: caso clínico

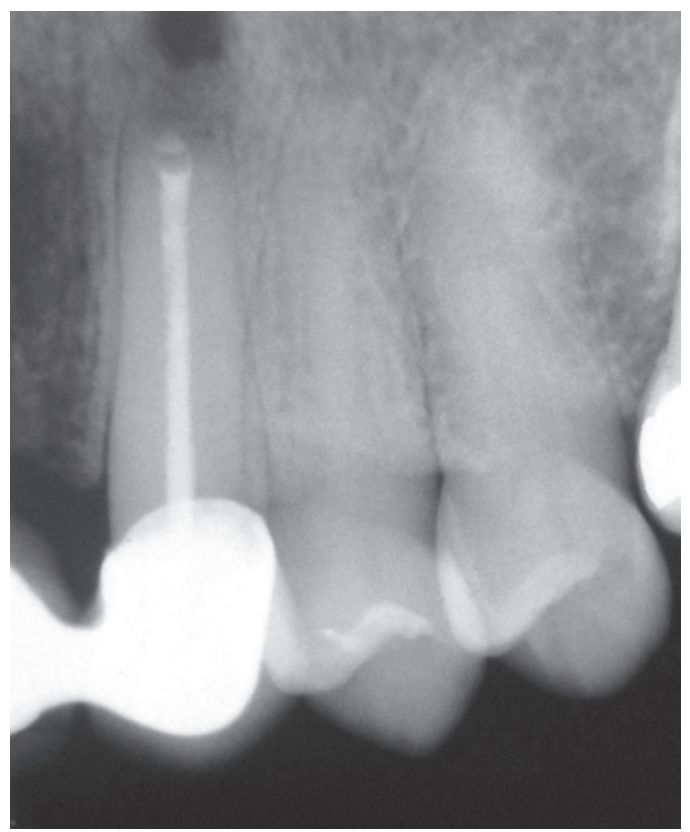

Figura 10. Aspecto radiográfico posquirúrgico Fuente: caso clínico

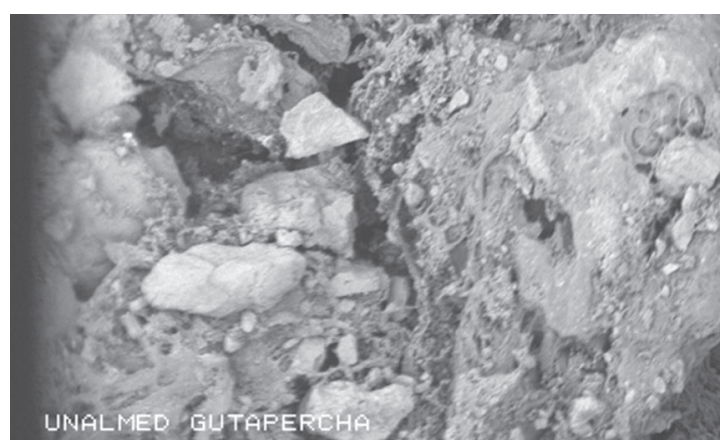

Figura 11. Fotografía bajo microscopía electrónica de barrido a $80 x$, de la gutapercha transapical que fue removida Fuente: caso clínico

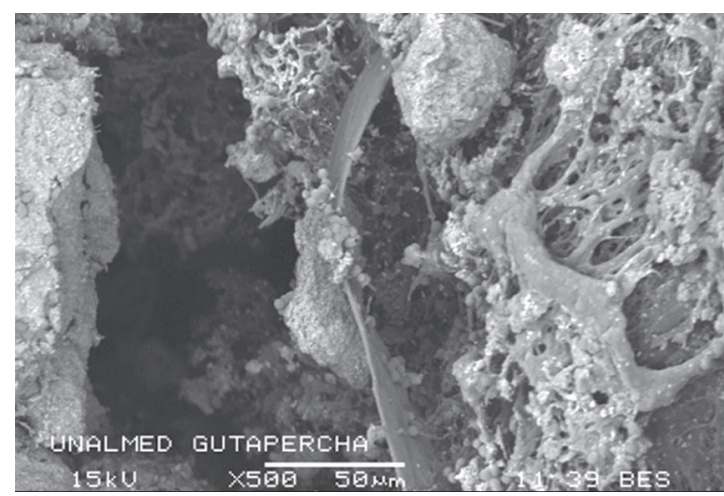

Figura 12. Fotografía bajo microscopía electrónica de barrido a 500x, de la gutapercha transapical que fue removida. Se observa la matriz de exopolisacáridos que envuelve las biopelículas

Fuente: caso clínico

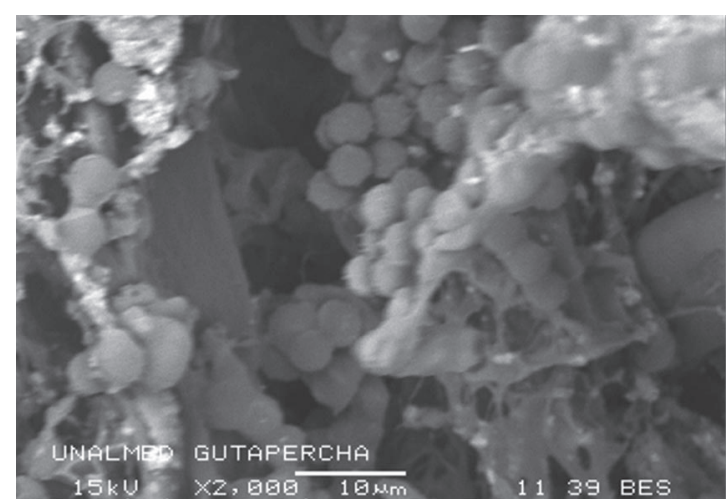

Figura 13. Fotografía bajo microscopía electrónica de barrido a 2000x, de la gutapercha transapical que fue removida Fuente: caso clínico

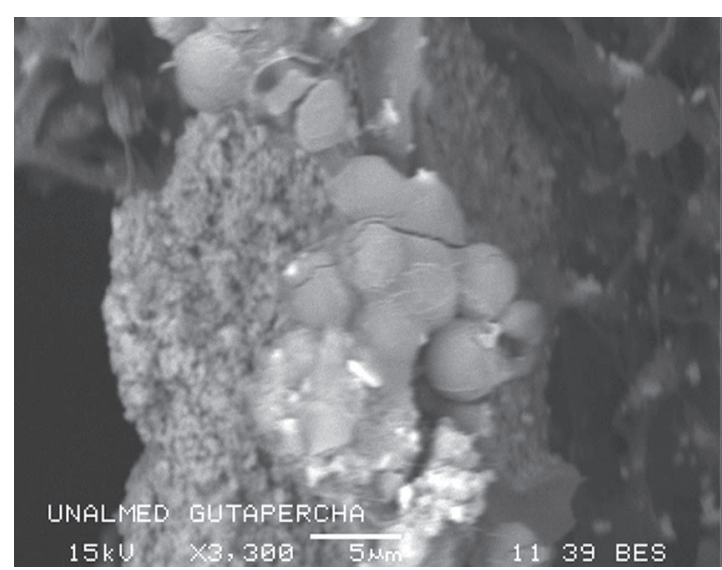

Figura 14. Fotografía bajo microscopía electrónica de barrido a 3300x, de la gutapercha transapical que fue removida Fuente: caso clínico 
Se observan las bacterias en forma de cocos agrupadas en biopelículas.

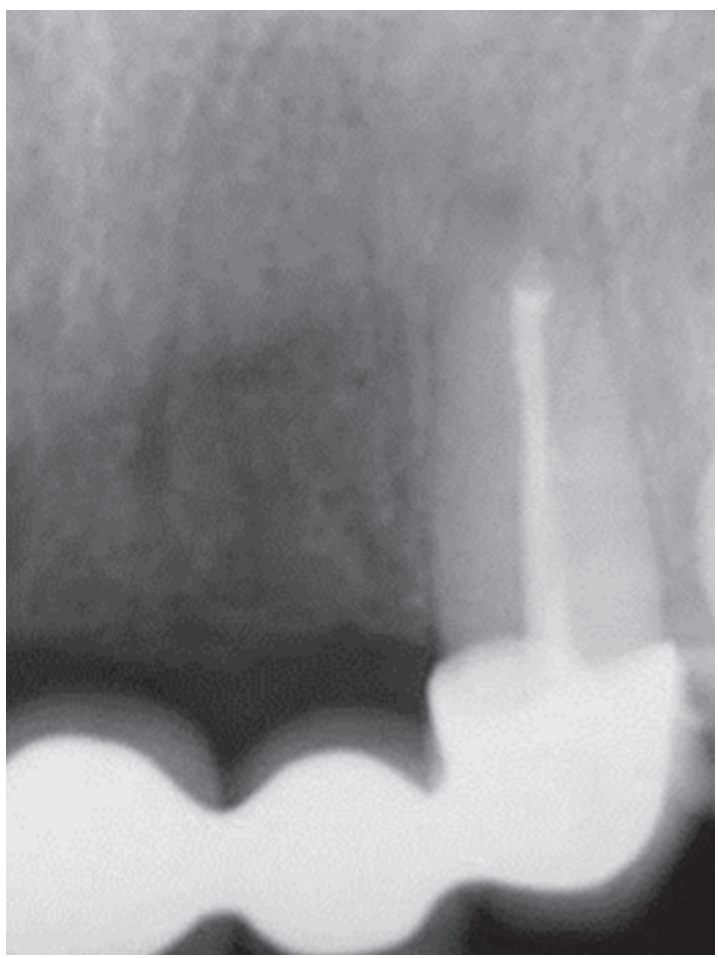

Figura 15. Aspecto radiográfico tres meses después de la cx apical

Fuente: caso clínico



Figura 16. Aspecto clínico tres meses después Fuente: caso clínico

\section{Discusión}

La formación de biopelículas en el interior del conducto radicular y en la superficie radicular externa del diente tiene grandes repercusiones en el pronóstico de largo plazo del tratamiento instaurado, dado que perpetúa la condición tratada y su eliminación representa un gran reto para el profesional [10-19].

El clínico no puede determinar la presencia de biopelículas en ninguna situación clínica en particular, aunque podría sospechar de su presencia en casos que no responden al tratamiento efectuado y en los que ha ocurrido una infección masiva del sistema de conductos radiculares, como después de exposiciones prolongadas por caries, conductos pobremente tratados y trayectos fistulosos [1-7, 9-16]. En vista de esto, cualquier diente a tratar debe ser considerado como potencial portador de biopelículas, y por tanto, deben ser empleadas todas las medidas terapéuticas necesarias para controlar la infección.

La instrumentación mecánica va a permitir la desorganización de la matriz de la biopelícula para la posterior acción de los agentes antimicrobianos [12-18]; no obstante, los patógenos pueden estar en zonas inaccesibles o muy profundas donde no van a ser removidos [14-21]. Si bien pudiéramos esperar que los irrigantes alcancen aquellas biopelículas ubicadas en zonas inaccesibles, los microorganismos allí embebidos van a estar protegidos por la barrera de difusión que representa la matriz de polisacáridos [1-8, 13-20].

Cuando nos referimos a las biopelículas extrarradiculares, las consideraciones son distintas, debido a que no van a ser afectadas por ningún procedimiento intrarradicular que sea realizado $[22,23]$. Aunque se podría pensar en el uso de antibioticoterapia sistémica para controlarlas o erradicarlas, el principal problema de las biopelículas es su conocida resistencia antibiótica [1-12], debido en gran medida a la barrera de difusión que representa la matriz de polisacáridos extracelulares [1-12, 13-19] y a la tasa de crecimiento disminuida que presentan los habitantes de dichas comunidades [17-22].

Otro punto de gran relevancia clínica en el tratamiento de las biopelículas extrarradiculares es que dichas infecciones pudieran remitir en sus síntomas agudos para luego producir episodios recurrentes $[22,23]$. Esto ocurre porque la terapia antibiótica solo es capaz de eliminar las células planctónicas, pero deja viables las formas sésiles, que se van a propagar en el interior de la biopelícula para continuar su diseminación y liberación de nuevas células planctónicas cuando la terapia antibiótica sea descontinuada [23]. 
Por otra parte, estas infecciones son difícilmente resueltas por el sistema inmune del hospedero; incluso, dicha respuesta es capaz de ocasionar daños en los tejidos en vecindad a las biopelículas [20-27].

En estas situaciones clínicas, la cirugía apical representa una manera eficaz y efectiva de desorganizar o eliminar a los microorganismos contenidos en estas organizaciones microbianas [14-27].

\section{Conclusión}

El resultado obtenido en este caso propone la cirugía apical como la opción clínica más efectiva para la desorganización o eliminación de los microorganismos agregados en biopelículas extrarradiculares, las cuales no pueden ser alteradas por la instrumentación, ni pueden ser afectadas por la acción de los agentes antimicrobianos usados durante el tratamiento de conductos.

\section{Referencias}

[1] Siqueira JF Jr. Aetiology of Root Canal Treatment Failure: Why Well-Treated Teeth Can Fail. Int Endodon J. 2001;34(1):1-10.

[2] Siqueira JF Jr, Lopes H. Bacteria on the Apical Root Surfaces of Untreated Teeth with Periradicular Lesions: A Scaning Electron Microscopy Study. Int endodon J. 2001;34(3):216-20.

[3] George S, Kisben A, Song K. The Role of Environmental Changes on Monospecies Biofilm Formation on Root Canal Wall by Enterococcus Faecalis. J Endod. 2005;31(12):867-72.

[4] Nair R. Light and Electron Microscopic Studies of Root Canal Flora and Periapical Lesions. J Endod. 1987;13(1):29-39.

[5] Molven O, Olsen I, Kerekes K. Scanning Electron Microscopy of Bacteria in the Apical Part of Root Canals in Permanent Teeth with Periapical Lesions. Endod Dent Traumatol. 1991;7(5):226-9.

[6] Distel J, Hatton J, Gillespie J. Biofilm Formation in Medicated Root Canals. J Endod. 2002;28(10):68993.

[7] Clegg M, Vertucci F, Walker C, Belanger M, Britto L. The Effect of Exposure to Irrigant Solutions on Apical Dentin Biofilm In Vitro. J Endod. 2006;32(5):434-7.

[8] Tronstad L, Barnett F, Cervone F. Periapical Bacterial Plaque in Teeth Refractory to Endodontic Treatment. Endodon Dent Traumatol. 1990;6(2):73-7.
[9] Lomcali G, Sen BH, Cankaya H. Scanning Electron Microscopic Observations of Apical Root Surfaces of Teeth with Apical Periodontitis. Endod Dent Traumatol. 1996;12(2):70-6.

[10] Walton R, Ardjmand K. Histological Evaluation of the Presence of Bacteria in Induced Periapical Lesions in Monkeys. J Endod. 1992;18(5):216-21.

[11] Noiri Y, Ehara A, Kawahara T, Takemura N, Ebisu S. Participation of Bacterial Biofilms in Refractary and Chronic Periapical Periodontitis. J Endod. 2002;28(10):679-83.

[12] Leonardo M, Rossi M, Silva L, Ito I, Bonifácio K. EM Evaluation of Bacterial Biofilm and Microorganism on the Apical External Root Surface of Human Teeth. J Endod. 2002;28(12):815-8.

[13] Sunde P, Olsen I, Debelian G, Tronstad L. Microbiota of Periapical Lesions Refractory to Endodontic Therapy. J Endod. 2002;28(4):304-10.

[14] Nair R, Henry S, Cano V, Vera J. Microbial Status of Apical Root Canal System of Human Mandibular First Molars with Primary Apical Periodontitis After "One-Visit" Endodontic Treatment. Oral Surg Oral Med Oral Pathol Oral Radiol Endodon. 2005;99(2):231-52.

[15] Nair R, Sjögren U, Krey G, Kahnberg K, Sundqvist G. Intraradicular Bacteria and Fungi in Root-Filled, Asymptomatic Human Teeth with Therapy-Resistant Periapical Lesions: A Long-Term Light and Electron Microscopic Follow-Up Study. J Endodon. 1990;16(12):580-8.

[16] Haapasalo M, Endal U, Zandi H, Coil J. Eradication of Endodontic Infection by Instrumentation and Irrigation Solutions. Endod Topics. 2005;10:72-102.

[17] Haapasalo M. Control and Elimination of Endodontic Infection. Roots International Magazine of Endodontology. 2006;1(1):15-22.

[18] Jefferson KK. What Drives Bacteria to Produce a Biofilm? FEMS Microbiol Lett. 2004;236(2):163-73.

[19] Donlan R, Costerton W. Biofilms: Survival Mechanisms of Clinically Relevant Microorganisms. Clin Microbiol Rev. 2002;15(2):167-93.

[20] Costerton JW, Cheng KJ, Geesey GG, Ladd TI, Nickel JC, Dasgupta M, et al. Bacterial Biofilms in Nature and Disease. Annu Rev Microbiol. 1987;41:435-64.

[21] Gilbert P, Das J, Foley I. Biofilms Susceptibility to Antimicrobials. Adv Dent Res. 1997;11(1):160-7.

[22] Tronstad L, Barnett F, Riso K, Slots J. Extraradicular Endodontic Infections. Endod Dent Traumatol. 1987;3(2):86-90.

[23] Tronstad L, Kreshtool D, Barnett F. Microbiological Monitoring and Results of Treatment of Extraradicular Endodontic Infection. Endod Dent Traumatol. 1990;6(3):129-36. 
[24] Costerton J, Lewandowski Z, Caldwell D, Korber D, Lappin-Scott H. Microbial Biofilms. Annu Rev Microbiol. 1995;49:711-45.

[25] Davey M, O’Toole G. Microbial Biofilms: From Ecology to Molecular Genetics. Microbiol Mol Biol Rev. 2000;64(4):847-67.
[26] Lasa I, Del Pozo J, Penaldes J, Leiva J. Bacterial Biofilms and Infection. An Sist Sanit Navar. 2005;28(2):163-75.

[27] Bowden G, Li Y. Nutritional Influences on Biofilm Development. Adv Dent Res. 1997;11(1):81-99. 